\title{
Floats, Pegs, AND the Transmission of Fiscal Policy
}

\author{
Giancarlo Corsetti \\ Cambridge University \\ Keith Kuester \\ Federal Reserve Bank of Philadelphia \\ Gernot J. Müller \\ University of Bonn
}

One of the most popular pieces of wisdom in economic policy is the idea that fiscal policy is more effective in a fixed exchange rate regime or a currency union than in a flexible exchange rate regime. In this paper, we revisit the theoretical foundations of the conventional wisdom on the relative effectiveness of fiscal policy under alternative exchange rate regimes, using a standard New Keynesian model of a small open economy. We do so by focusing our analysis on the inherent link between the macroeconomic effects of a short-run stimulus and private expectations about medium-run monetary and fiscal policy developments. We do not, however, deviate from the assumption of perfect credibility of the peg, and we do not consider the case of prospective deficit monetization, discussed in an important contribution by Dornbusch (1980). ${ }^{1}$ Rather, we look at

We thank our discussant Fabio Ghironi, an anonymous referee, as well as Olivier Blanchard, Jordi Gali, Janet Kondeva, Jim Nason, and the participants at the Conference for comments. The views expressed here do not necessarily represent those of the Federal Reserve Bank of Philadelphia or the Federal Reserve System.

1. According to Dornbusch, the prediction that a fiscal expansion causes the exchange rate to appreciate is an unappealing feature of the Mundell-Fleming model, in apparent contrast with the practical experience in policymaking. To address this issue, Dornbusch encompasses medium-term monetary developments in the model, focusing on the case in which government expansions in the short run foreshadow deficit monetization over the medium run. The anticipation of a future monetary expansion already weakens the exchange rate in the short run.

Fiscal Policy and Macroeconomic Performance, edited by Luis Felipe Céspedes and Jordi Galí, Santiago, Chile. (C) 2013 Central Bank of Chile. 
plausible monetary and fiscal policy regimes, assumed to remain in place over the medium run.

Specifically, the New Keynesian model calls attention to the real long-term rate as a core indicator of the overall stance of stabilization policy: for private demand to increase in response to a shock, this rate must fall (see Woodford, 2003). Then, under the expectation hypothesis, long-term rates reflect the entire path of (current and future anticipated) monetary and fiscal decisions, via the effects of the latter on short-term rates over time, as stressed by Corsetti, Meier, and Müller (2009). Based on this consideration, we are able to derive sharp predictions regarding the macroeconomic dynamics following any given fiscal expansion in a small open economy, as a function of the regimes governing the evolution of fiscal policy and monetary or exchange rate policy.

The main conclusion of our analysis is that fiscal policy is not necessarily less effective under flexible exchange rates. Specifically, while approximating the central bank's behavior with a Taylor rule, we generate two findings. First, a high degree of monetary accommodation can greatly amplify the expansionary effects of a fiscal stimulus under flexible rates, up to making fiscal stimulus approximately as powerful as under a peg. Second, a plausible regime of medium-run fiscal consolidation, in which both spending and taxes are adjusted after the initial stimulus so as to stabilize debt, can actually undermine the ranking according to the conventional wisdom. The transmission mechanism for the case of a float is analyzed in detail by Corsetti, Meier, and Müller (2009), who show that, everything else equal, the long-term real interest rate tends to fall if agents anticipate a contraction in government spending in the near future, boosting private and thus aggregate demand. A specific contribution of this paper is to show that a fall in long real rates in response to a fiscal expansion is not possible under a peg, whether or not agents anticipate spending cuts in the medium term.

We provide a simple analytical characterization of the initial effect of temporary shocks (including fiscal ones) on the long-term rate under an exchange rate peg. Namely, assuming complete financial markets and additively separable utility, we show that under a peg the long-term real rate moves one-to-one with the initial (unexpected) change in the consumer price index (CPI) up to a firstorder approximation. In other words, the initial bout of inflation in response to a fiscal expansion approximates the rise in long-term real rates on impact. In turn, this rise in long-term real rates drives 
down consumption demand proportionately. ${ }^{2}$ The crowding out of consumption thus reduces the multiplier. Different outcomes, instead, are possible under a float, depending on the interaction of monetary and fiscal policy in the medium run.

A corollary of our analysis is that under a peg, short-term real rates and long-term real rates comove negatively in response to a fiscal shock: the latter necessarily rise on impact, even if the former fall oneto-one with the inflation rate. This characterization of the transmission mechanism casts doubts on the argument underlying the so-called Walters critique. ${ }^{3}$ According to this critique, under a fixed exchange rate regime, exogenous cyclical shocks (including fiscal shocks) that cause inflation are bound to be amplified by the implied endogenous procyclical movements in the real interest rate. A fixed exchange rate regime is therefore inherently destabilizing. This argument relies on the maintained (but incorrect) assumption that real rates necessarily move in the same direction over the whole maturity structure.

We carry out a robustness analysis by enriching the baseline New Keynesian small open economy framework with features capturing financial imperfections and frictions. After establishing that our main conclusions hold under incomplete financial markets, we study the case of economies with limited asset market participation-a fraction of households are excluded from financial markets, possibly because of (nonmodeled) access costs. Fiscal stabilization is typically motivated by pointing out that a significant fraction of households may face financial constraints, making monetary policy less potent. We show that our main results carry over to this environment, where fiscal policy becomes more effective overall.

Our results provide a fresh perspective on the relative merits of fiscal policy as a stabilization tool under fixed and floating exchange rates, as well as a rationale for why fiscal policy is used as an actual stabilization tool under both exchange rate regimes. For analytical purposes, we focus on the transmission of exogenous innovations in government spending, but our results also shed light on how an endogenous policy response to shocks is likely to affect the economy under a peg or float. Specifically, to the extent that variations in

2. The constant of proportionality depends on the curvature of the utility function. While this condition does not hold exactly if markets are incomplete or if preferences are not additively separable, the main insight of a positive relation between initial unexpected inflation and the movement in the long-term rate remains valid in more general model specifications.

3. See Newman, Milgate, and Eatwell (1992); Buiter, Corsetti, and Pesenti (1998). 
government spending in response to shocks are partly reversed in the future, they are likely to be at least as effective a stabilization tool under floating as under fixed exchange rates.

This paper is organized as follows. section 1 reviews the conventional wisdom based on the traditional Mundell-Fleming model. section 2 presents our New Keynesian model of a small open economy, and section 3 provides a brief overview of the linearized equilibrium conditions. section 4 then reconsiders the conventional wisdom in the New Keynesian framework, focusing on the special case of an exogenous autoregressive fiscal disturbance. section 5 derives analytical results regarding the fiscal transmission mechanism. section 6 carries out experiments for a general specification of fiscal policy with endogenous correction of both taxes and spending. section 7 explores the robustness of our results in the presence of financial frictions, and section 8 concludes.

\section{The Conventional Wisdom}

The conventional wisdom typically refers to the textbook version of the Mundell-Fleming model, as illustrated graphically by figure 1 . Aggregate demand, $Y$, is measured on the horizontal axis, and the nominal interest rate is measured on the vertical axis. The downward sloping line is the IS curve, derived from the equilibrium condition that investment equals savings, with output expresssed as a declining function of the interest rate. The position of the IS curve depends on the level of the exchange rate: with preset prices, a nominal depreciation (which in this case is the same as a real depreciation) moves the IS to the right, through a positive competitiveness effect on real exports. In the background of this curve, the exchange rate is determined by the uncovered interest parity condition, so that a fixed exchange rate requires equality between the domestic and foreign interest rates in nominal terms. Under a floating rate, one needs to make an assumption about agents' expectations of future exchange rates. Without loss of generality, for our purpose it is analytically convenient to assume that the exchange rate follows a random walk. ${ }^{4}$ Money demand is a positive function of output and a negative function of the nominal interest rate.

4. Many textbook models assume stationary expectations instead: the exchange rate in the future is expected to revert to some given value. 
Figure 1. Expansion of Government Spending in Textbook Mundell-Fleming Model

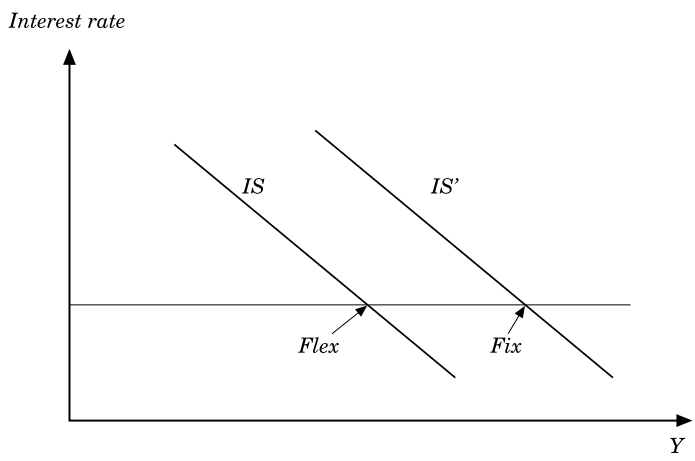

Source: Authors' construction.

In a small open economy (in which foreign interest rate and prices are given), a spending expansion has a large multiplier effect on output under fixed exchange rates, while it just crowds out net exports one to one under flexible exchange rates. The reason for these differential results is a different degree of monetary accommodation across the two regimes. Under a peg, the central bank is committed to stemming any change in the demand for money that may compromise the sustainability of the official exchange rate parity. Hence, there must be full monetary accommodation. If government interventions drive up employment and income, households and firms raise their demand for cash, and the central bank has to raise its money supply by the same amount. Otherwise, the interest rate would rise, and a higher interest rate would tend to make the currency appreciate (via the uncovered interest parity condition). This implies a multiplier larger than one for the case of a peg.

Under a flexible rate regime, the central bank is not committed to any particular exchange rate parity. If a spending expansion were successful in raising employment, incomes, and the demand for money, there would be an upward pressure on interest rates that would in turn make the currency appreciate. A stronger currency reduces aggregate demand and income by crowding out net exports, which then counteracts the effects of the initial stimulus on interest rates. Since in equilibrium there cannot be any upward pressure on the interest rate 
or the exchange rate, on impact the latter must appreciate by enough to rule out any change in the level of aggregate demand, output, and money demand. A government expansion therefore results exclusively in nominal and real appreciation and a different composition of final demand, with more public demand and fewer exports. ${ }^{5}$

Such sharp results are sensitive to the parameterization of expectations. Assuming a stationary exchange rate, for instance, the impact appreciation of the exchange rate under a floating regime would create expectations of depreciation in the future. In equilibrium, the domestic interest rate would rise above the foreign rate, with crowding out effects on domestic investment. The substance of the above analysis would not be affected, but there would be some response in equilibrium policy rates and the composition of final demand, whereby more government spending would imply both lower net exports and lower investment. A further observation is that when we include price dynamics in the model, the inflationary consequences of a spending expansion should be more pronounced under a fixed exchange rate.

The presumption that the degree of monetary accommodation is necessarily higher under a peg is nonetheless controversial, even in the traditional literature. Implicit in the analysis by Dornbusch (1980), for instance, is the notion that, in practice, monetary accommodation tends to be quite pronounced under a floating regime-a position motivated by the empirical observation that the nominal exchange rate tends to depreciate with fiscal expansions. ${ }^{6}$

\section{A Small Open Economy Model}

This section outlines a New Keynesian small open economy model similar to Galí and Monacelli (2005) and Ghironi (2000). Our exposition follows Corsetti, Meier, and Müller (2009), except that, for clarity of exposition, we assume complete international financial markets in the baseline scenario. In a later section, we consider alternative assumptions regarding the set of internationally traded

5. In this simple exercise, monetary accommodation works through changes in the money supply, while the interest rate actually remains constant in both regimes. The analysis of the flexible exchange rate regime is indeed typically carried out under the assumption of a constant money supply.

6. See Corsetti, Meier, and Müller (2010) for recent evidence. 
assets and the fraction of households that participate in domestic asset markets. Our exposition focuses on the domestic economy and its interaction with the rest of the world. ${ }^{7}$

\subsection{Final-Good Firms}

The final consumption good, $C_{t}$, is a composite of intermediate goods produced by a continuum of monopolistically competitive firms both at home and abroad. We use $j \in[0,1]$ to index intermediategood firms and their products and prices. Final-good firms operate under perfect competition and purchase domestically produced intermediate goods, $Y_{H, t}(j)$, as well as imported intermediate goods, $Y_{F, t}(j)$. Final-good firms minimize expenditures subject to the following aggregation technology:

$$
C_{t}=\left\langle(1-\omega)^{\frac{1}{\sigma}}\left\{\left[\int_{0}^{1} Y_{H, t}(j)^{\frac{\varepsilon-1}{\varepsilon}} d j\right]^{\frac{\varepsilon}{\varepsilon-1}}\right\}^{\frac{\sigma-1}{\sigma}}+\omega^{\frac{1}{\sigma}}\left\{\left[\int_{0}^{1} Y_{F, t}(j)^{\frac{\varepsilon-1}{\varepsilon}} d j\right]^{\frac{\varepsilon}{\varepsilon-1}}\right\}^{\frac{\sigma-1}{\sigma}}\right\rangle^{\frac{\sigma}{\sigma-1}},
$$

where $\sigma$ measures the trade-price elasticity, that is, the extent of substitution between domestically produced goods and imports for a given change in the terms of trade. The parameter $\varepsilon>1$ measures the price elasticity across intermediate goods produced within the same country, while $\omega$ measures the weight of imports in the production of final consumption goods, where a value lower than one-half corresponds to home bias in consumption.

Expenditure minimization implies the following price indexes for domestically produced intermediate goods and imported intermediate goods, respectively:

$$
\begin{aligned}
& P_{H, t}=\left[\int_{0}^{1} P_{H, t}(j)^{1-\varepsilon} d i\right]^{\frac{1}{1-\varepsilon}} ; \\
& P_{F, t}=\left[\int_{0}^{1} P_{F, t}(j)^{1-\varepsilon} d i\right]^{\frac{1}{1-\varepsilon}} .
\end{aligned}
$$

7. Our small open economy can be interpreted as the limiting case, within a twocountry world, of an economy that has a relative size of zero; see De Paoli (2009). 
By the same token, the consumption price index is

$P_{t}=\left[(1-\omega) P_{H, t}^{1-\sigma}+\omega P_{F, t}^{1-\sigma}\right]^{\frac{1}{1-\sigma}}$.

Regarding the rest of the world, we assume an isomorphic aggregation technology. The law of one price is assumed to hold at the level of intermediate goods, such that

$P_{F, t} \mathrm{NER}_{t}=P_{t}^{*}$,

where $\mathrm{NER}_{t}$ is the nominal exchange rate (the price of domestic currency in terms of foreign currency) and $P_{t}^{*}$ denotes the price index of imports measured in foreign currency. It corresponds to the foreign price level, as imports account for a negligible fraction of rest-of-world consumption. For future reference, we define the terms of trade and the real exchange rate as

$$
S_{t}=\frac{P_{H, t}}{P_{F, t}}
$$

and

$Q_{t}=\frac{P_{t} \mathrm{NER}_{t}}{P_{t}^{*}}$

respectively. While the law of one price holds throughout, deviations from purchasing power parity (PPP) are possible in the short run, due to home bias in consumption. Below we consider the dynamics of the model around a symmetric steady state such that PPP holds in the long run.

\subsection{Intermediate-Good Firms}

Intermediate goods are produced on the basis of the following production function: $Y_{t}(j)=H_{t}(j)$, where $H_{t}(j)$ measures the amount of labor employed by firm $j$.

Intermediate-good firms operate under imperfect competition. We 
assume that price setting is constrained exogenously by a discretetime version of the mechanism suggested by Calvo (1983). Each firm has the opportunity to change its price with a given probability $1-\xi$. Given this possibility, a generic firm $j$ will set $P_{H, t}(j)$ in order to solve

$$
\max E_{t} \sum_{k=0}^{\infty} \xi^{k} \rho_{t, t+k}\left[Y_{t, t+k}(j) P_{H, t}(j)-W_{t+k} H_{t+k}(j)\right],
$$

where $\rho_{t, t+k}$ denotes the stochastic discount factor and $Y_{t, t+k}(j)$ denotes demand in period $t+k$, given that prices have been set optimally in period $t . E_{t}$ denotes the expectations operator.

\subsection{Households}

For our baseline scenario, we assume that there is a representative household that ranks sequences of consumption and labor effort, $H_{t}=\int_{0}^{1} H_{t}(j) d j$, according to the following criterion:

$$
E_{t} \sum_{k=0}^{\infty} \beta^{k}\left(\frac{C_{t+k}^{1-\gamma}}{1-\gamma}-\frac{H_{t+k}^{1-\varphi}}{1-\varphi}\right) .
$$

We assume that the household trades a complete set of statecontingent securities with the rest of the world. Letting $\Xi_{t+1}$ denote the payoff in units of domestic currency in period $t+1$ to the portfolio held at the end of period $t$, the household's budget constraint is given by

$$
W_{t} H_{t}+\Upsilon_{t}-T_{t}-P_{t} C_{t}=E_{t}\left(\rho_{t, t+1} \Xi_{t+1}\right)-\Xi_{t}
$$

where $T_{t}$ and $\Upsilon_{t}$ denote lump-sum taxes and profits of intermediategood firms, respectively.

\subsection{Monetary and Fiscal Policy}

The specification of monetary policy depends on the exchange rate regime. Under flexible exchange rates, we assume that the central bank sets the nominal short-term interest rate following a Taylor-type rule:

$$
\log \left(R_{t}\right)=\log \left(R_{t}\right)+\phi_{\pi}\left(\Pi_{H, t}-\Pi_{H}\right),
$$


where $\Pi_{H, t}=P_{H, t} / P_{H, t-1}$ measures domestic inflation and variables without a time subscript refer to the steady-state value of a variable (here as well as in the following equations). In this case, the nominal exchange rate is free to adjust in accordance with the equilibrium conditions implied by the model. Several monetary regimes are possible under a float, and the specification of monetary policy is key for our comparison of fiscal policy transmission under pegs and floats.

Under an exchange rate peg, the monetary authorities are required to adjust the policy rate so that the exchange rate remains constant at its steady-state level. A feasible policy that ensures this, as well as equilibrium determinacy, is given by

$$
\log \left(R_{t}\right)=\log \left(R_{t}^{*}\right)+\phi_{\mathrm{NER}} \log \left(\frac{\mathrm{NER}_{t}}{\mathrm{NER}}\right),
$$

with $\phi_{\mathrm{NER}}>0 .^{8}$

With regard to fiscal and budget policy, we assume that government spending falls on an aggregate of domestic intermediate goods only:

$$
G_{t}=\left[\int_{0}^{1} Y_{H, t}(j)^{\frac{\varepsilon-1}{\varepsilon}} d j\right]^{\frac{\varepsilon}{\varepsilon-1}} .
$$

We also posit that intermediate goods are assembled so as to minimize costs. The price index for government spending is thus given by $P_{H, t}$. Government spending is financed either through lump sum taxes, $T_{t}$, or through the issuance of nominal one-period debt, $D_{t}$. The government's period budget constraint reads as follows:

$$
R_{t}^{-1} D_{t+1}=D_{t}+P_{H, t} G_{t}-T_{t} .
$$

Defining $D_{t}^{r}=D_{t} / P_{t-1}$ as a measure for real, beginning-of-period, debt and $T_{t}^{r}=T_{t} / P_{t}$ as taxes in real terms, we posit that fiscal policy is described by the following feedback rules from debt accumulation to the level of spending and taxes:

$$
G_{t}=(1-\rho) G+\rho G_{t-1}-\psi_{G} D_{R t}+\varepsilon_{t}, T_{R t}=\psi_{T} D_{R t},
$$


where $\varepsilon_{t}$ measures an exogenous, independent and identically distributed (i.i.d.) shock to government spending. The $\psi$ parameters capture the responsiveness of spending and taxes to government spending and debt. Standard analyses of the fiscal transmission typically assume that $\psi_{G}=0$. When taxes are lump-sum, Ricardian equivalence obtains in this case, as the path of government spending is exogenously given, and the time path of debt and taxes becomes irrelevant for the real allocation. Compared with this benchmark, allowing for $\psi_{G}>0$ fundamentally alters the fiscal transmission mechanism; see Corsetti, Meier, and Müller (2009). For once, strictly speaking, Ricardian equivalence fails in this case, even when taxes are lump sum. A debt-financed cut in taxes dynamically leads to an adjustment in real spending, which affects the real allocation. Moreover, the time profile of adjustment affects the intertemporal price of consumption, with sharp implications for macroeconomic dynamics. Below we analyze the fiscal transmission mechanism in light of these considerations, contrasting results under a floating exchange rate regime with those obtained under a pegged exchange rate regime.

\subsection{Equilibrium}

Equilibrium requires that firms and households behave optimally for given initial conditions, exogenously given developments in the rest of the world, and government policies. Market-clearing conditions also need to be satisfied. At the level of each intermediate good, supply must equal total demand stemming from final-good firms, the rest of the world, and the government:

$$
Y_{t}(j)=\left[\frac{P_{H, t}(j)}{P_{H, t}}\right]^{-\varepsilon}\left[(1-\omega)\left(\frac{P_{H, t}}{P_{t}}\right)^{-\sigma} C_{t}+\omega\left(\frac{P_{H, t}^{*}}{P_{t}}\right)^{-\sigma} C_{t}^{*}+G_{t}\right],
$$

where $P_{H, t}^{*}$ and $C_{t}^{*}$ denote the price index of domestic goods expressed in foreign currency and rest-of-world consumption, respectively. It is convenient to define an index for aggregate domestic output:

$$
Y_{t}=\left[\int_{0}^{1} Y_{t}^{\frac{\varepsilon-1}{\varepsilon}}(j) d j\right]^{\frac{\varepsilon}{\varepsilon-1}}
$$


Substituting for $Y_{t}(j)$ using equation (14) gives the aggregate relationship,

$Y_{t}=(1-\omega)\left(\frac{P_{H, t}}{P_{t}}\right)^{-\sigma} C_{t}+\omega\left(\frac{P_{H, t}^{*}}{P^{*}}\right)^{-\sigma} C_{t}^{*}+G_{t}$.

We also define the trade balance in terms of steady-state output:

$T B_{t}=\frac{1}{Y}\left(Y_{t}-\frac{P_{t}}{P_{H, t}} C_{t}-G_{t}\right)$.

In what follows, we consider a first-order approximation of the equilibrium conditions of the model around a deterministic steady state with balanced trade, zero debt, zero inflation, and purchasing power parity. Further, we consider only shocks that originate in the domestic economy and thus do not affect the rest of the world.

\section{Linearized Equilibrium Conditions}

This section presents a set of equilibrium conditions that can be used to approximate the equilibrium allocation in response to government spending shocks in the neighborhood of the steady state. Lowercase letters indicate percentage deviations from steady state, while a hat indicates that such deviations are measured in percent of steady-state output. Details of the derivation can be found in appendixes A and B. Under a float and for an exogenously given path of government spending, three equations are sufficient to characterize the equilibrium: a dynamic IS equation, the New Keynesian Phillips curve, and a characterization of monetary policy. ${ }^{9} \mathrm{~A}$ three-equation representation of the equilibrium is not possible, however, for a richer specification of fiscal policy featuring an endogenous feedback effect from debt to spending or in case of an exchange rate peg.

9. This is often referred to as the canonical representation of the New Keynesian model (see, for example, Galí and Monacelli, 2005). Our representation differs from Galí and Monacelli (2005) because they abstract from government spending. We prefer to represent the canonical form using output, rather than the output gap, in view of the fact that changes in government spending also alter the natural level of output. Gali and Monacelli (2008) consider a very similar setup, but focus on the special case in which the intertemporal elasticity of substitution and the trade price elasticity are equal to one. 
The dynamic IS equation is given by:

$y_{t}=E y_{t+1}-\frac{(1-\chi)^{\bar{\omega}}}{\gamma}\left(r_{t}-E_{t} \pi_{H, t+1}\right)-E_{t} \Delta \hat{g}_{t+1}$,

where $\pi_{H, t}$ denotes domestic (producer price) inflation, $\hat{g}_{t}$ denotes the deviation of government spending from steady state measured in percent of steady-state output, $\chi$ measures the government spendingto-output ratio in the steady state, and

$\bar{\omega}=1+\omega(2-\omega)(\sigma \gamma-1)$.

The open-economy New Keynesian Phillips curve is given by

$\pi_{H, t}=\beta E_{t} \pi_{H, t+1}+\kappa\left[\varphi+\frac{\gamma}{(1-\chi) \varpi}\right] y_{t}-\kappa \frac{\gamma}{(1-\chi) \varpi} \hat{g}_{t}$,

where $\kappa=(1-\beta \xi)(1-\xi) / \xi$.

Either monetary policy is characterized by an interest rate feedback rule (in which case the nominal exchange rate is free to adjust), or monetary authorities adjust the policy rate so as to peg the exchange rate to its steady-state level. Formally, we have

$r_{t}=\phi_{\pi} \pi_{H}$

or

$r_{t}=\phi_{N E R} \mathrm{NER}_{t}$.

Variables pertaining to the rest of the world are zero in terms of deviations from the steady state, as we only consider shocks in the domestic economy.

The evolution of public debt, government spending, and taxes is given by

$$
\begin{aligned}
& \beta \hat{d}_{t+1}^{r}=\hat{d}_{t}^{r}+\chi \omega s_{t}+\hat{g}_{t}-\hat{t}_{t}^{r} \\
& \hat{g}_{t}=\rho \hat{g}_{t-1}-\psi_{G} \hat{d}_{t}^{r}+\varepsilon_{t},
\end{aligned}
$$


and

$\hat{t}_{t}^{r}=\psi_{T} \hat{d}_{t}^{r}$.

To fully specify the equilibrium dynamics, we relate the nominal exchange rate to the dynamics of output and inflation as follows. The definition of the terms of trade, $s_{t}=p_{H, t}-p_{F, t}$, and the law of one price imply

$s_{t}=p_{H, t}+\mathrm{NER}_{t}$.

Using the good-market-clearing condition and the risk-sharing condition, we can express the terms of trade in terms of output net of government spending:

$\frac{1-\chi}{\gamma} \varpi s_{t}=-\left(y_{t}-\hat{g}_{t}\right)$.

Given initial conditions and a sequence for innovations to government spending, $\left\{\varepsilon_{t}\right\}_{t=0}^{\infty}$, equations (17) to (24) pin down a sequence for nine variables, $\left\{y_{t}, \pi_{H, t}, p_{H, t}, \hat{g}_{t}, e_{t}, s_{t}, \hat{t}_{t}^{r}, d_{t+1}\right\}_{t=0}^{\infty}$, where $\pi_{H, t}=p_{H, t}-p_{H, t-1}$.

\section{Revisiting the Conventional Wisdom: Exchange Rate Regime and Monetary Accommodation}

Theoretical studies of the macroeconomic effects of fiscal policy typically assume that government spending follows an exogenously given first-order autoregressive, or AR(1), process. In our framework, this assumption corresponds to the case of no feedback from debt accumulation to spending, $\psi_{G}=0$, which, as mentioned, implies Ricardian equivalence. While restrictive, this conventional parameterization provides a useful starting point for our analysis. Specifically, we take up the issue of how and why the exchange rate regime may alter the transmission of an autoregressive spending shock matched by higher lump-sum taxes. We use model simulations to show that under standard assumptions on parameter values, this basic exercise supports a particular aspect of the conventional wisdom, namely, that fiscal 
policy is more effective in stimulating economic activity under fixed exchange rates than under floating exchange rates (in which the central bank follows a Taylor rule).

For our numerical experiments, we adopt the following parameter values. A period in the model corresponds to one quarter. The discount factor, $\beta$, is set to 0.99 . We assume that the coefficient of relative risk aversion, $\gamma$, and the inverse of the Frisch elasticity of labor supply, $\varphi$, take the value of one. The trade price elasticity, $\sigma$, is also set equal to unity. Regarding openness, we assume $\omega=0.3$. As price rigidities are bound to play an important role in the transmission of government spending shocks, we assume a fairly flat Phillips curve by setting $\xi=0.9$, a value that implies an average price duration of 10 quarters. This parameterization conflicts with evidence from microeconomic studies such as Nakamura and Steinsson (2008). Nonetheless, the choice of a relatively high degree of price rigidity seems appropriate in the context of our framework, since we abstract from several model features that would imply a flatter Philips curve for any given value of $\xi$ (for example, nonconstant returns to scale in the variable factor of production or nonconstant elasticities of demand). ${ }^{10} \mathrm{We}$ also abstract from wage rigidities. We set $\varepsilon=11$, such that the steadystate markup is equal to 10 percent. In specifying monetary policy, we set $\phi_{\pi}=1.5$. As discussed below, this parameter plays a central role in the transmission of fiscal shocks. Finally, the average share of government spending in GDP is set to 20 percent, and we assume that the persistence of government spending is $\rho=0.9$.

Figure 2 displays the impulse response to an exogenous increase in government spending by 1 percent of GDP, for two economies that are identical in all respects except for the exchange rate (and thus the monetary) regime. The responses of output and government spending are measured in percent of steady-state output. The responses of the other variables are measured in percentage deviations from steady state. The horizontal axes indicate quarters. The solid line refers to the exchange rate peg, while a dashed line marks the floating regime. The AR(1) process of government spending, identical across exchange rate regimes, is shown in panel $\mathrm{A}$.

10. See Galí, Gertler, and López-Salido (2001) or Eichenbaum and Fisher (2007) for further discussion of how real rigidities interact with nominal price rigidities in the context of the New Keynesian model. The latter study also considers a nonconstant price elasticity of demand, which further increases the degree of real rigidities. 


\section{Figure 2. Effect of a Government Spending Shock: Peg versus Float ${ }^{a}$}

\section{A. Goverment spending}

Percent of steady-state output

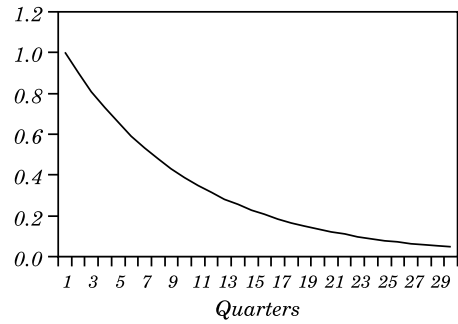

C. Inflation

Percent deviation from steady state

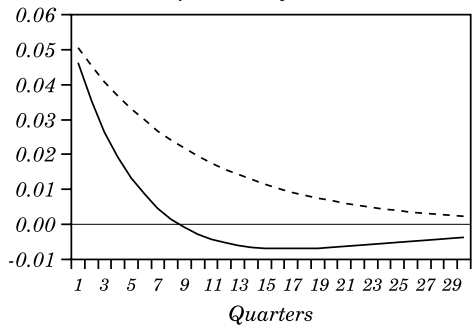

E. Price level

Percent deviation from steady state

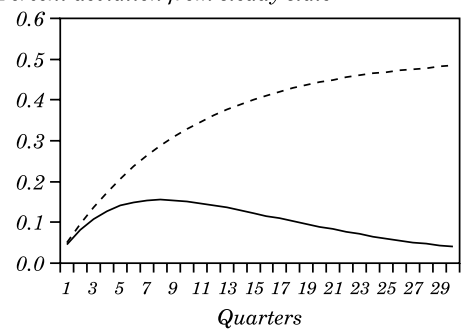

B. Output

Percent of steady-state output

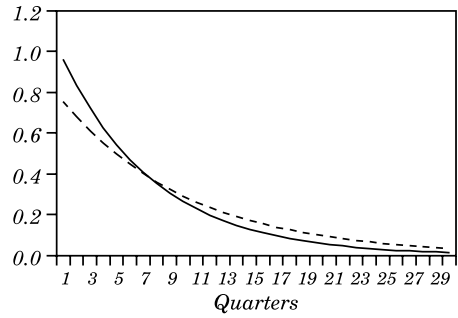

D. Policy rate

Percent deviation from steady state

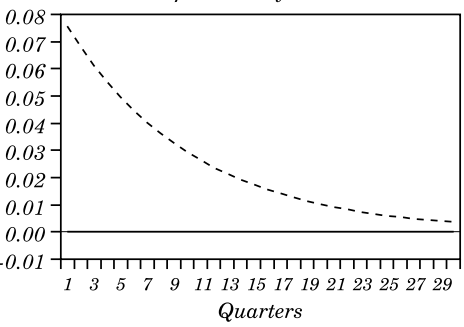

F. Exchange rate

Percent deviation from steady state

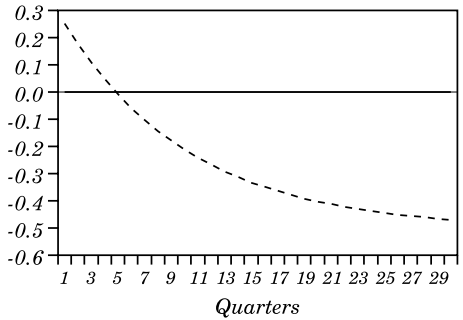

- - Float $\longrightarrow$ Peg

Source: Authors' construction.

a. Floating exchange rates with $\phi_{\pi}=1$.5. Inflation and price level pertain to the price of domestically produced goods. 
A first notable result is that, in both regimes, the response of output (panel B) is positive, but smaller than unity throughout. This is quite different from the Mundell-Fleming model for a small open economy with perfect capital mobility, which predicts that government spending multipliers on output should be larger than one under a peg and zero under a float. Our results do agree with the conventional theory in relative terms: in response to a positive (autoregressive) fiscal shock, GDP under the peg exceeds that under the float by approximately 25 percent on impact, and the response of GDP remains stronger under the peg for the first couple of quarters after the initial impulse.

Further notable results shown in figure 2 concern the response of inflation and the price level. On impact, the response of domestic inflation (panel C) is positive irrespective of the exchange rate regime. Over time, however, inflation follows divergent paths. Under a peg, inflation falls below its steady-state value after about two years, whereas it remains positive throughout under a float. This has direct implications for the policy rate. Under a float, the Taylor rule implies that the policy rate rises sharply on impact and only gradually reverts to its steady-state level. In nominal terms, the policy rate under a float thus remains above the constant nominal rate, dictated by the need to maintain the peg. Moreover, as the Taylor principle is satisfied under a float, real short-term interest rates (not shown) rise above steady-state levels throughout the expansionary fiscal stance, such that the long-term real interest rate rises as well.

The differential behavior of inflation also maps into an apparent long-run divergence in the price level for domestically produced goods $\left(p_{H, t}\right)$ and thus in the nominal exchange rate. With the central bank following a Taylor rule under a float, monetary authorities adjust the policy rate in response to the growth rate of prices, and nominal prices drift to a permanently higher level. Since purchasing power parity (PPP) must be satisfied in the long-run, the nominal exchange rate depreciates proportionally over time. Thus, both the level of domestic prices and the nominal exchange rate display a unit root behavior under a float.

When the exchange rate remains (credibly) pegged to its initial level, long-run PPP requires domestic prices to revert to their initial steady-state level. Inflation must therefore fall below its steady-state rate after the initial positive bout. In the short run, firms respond to the additional demand from the government by raising prices, which makes them less competitive in the world market. As government 
spending progressively reverts to its initial level, domestic firms need to regain competitiveness: they reoptimize prices by setting lower prices as government demand falls.

In figure 2, government spending is exogenously determined and identical across exchange rate regimes, so larger output effects under a peg reflect a relatively more accommodative monetary policy, as maintained by conventional wisdom. Given the role that monetary accommodation plays in the transmission mechanism, our results are somewhat sensitive to the parameterization of the monetary policy rule under a float, a point illustrated by figure 3 . In this figure, we contrast results for high and low values of the coefficient $\phi_{\pi}$. With a coefficient as high as $\phi_{\pi}=3.00$, implying that the central bank targets near price stability, the impact multiplier is about 0.6 , which is more in line with the traditional MundellFleming view of relatively weak output effects of government spending under a float. Conversely, a lower coefficient of $\phi_{\pi}=1.01$, indexing a mild reactivity of the central bank to current inflation, yields very similar impact multipliers under a float and under a peg (and cumulative multipliers, obtained by summing up the output effects over time, are actually larger).

In light of the above results, we can rephrase the key lesson from the conventional wisdom: since the effectiveness of fiscal policy depends on the degree of monetary accommodation, comparing fiscal transmission across exchange rate regimes requires a precise specification of how monetary policy is and will be conducted. The New Keynesian model provides a clear and transparent framework for accomplishing this. 
Figure 3. Effect of a Government Spending Shock for alternative values of $\phi_{\pi}$ : Peg versus Float

\section{A. Goverment spending}

Percent of steady-state output

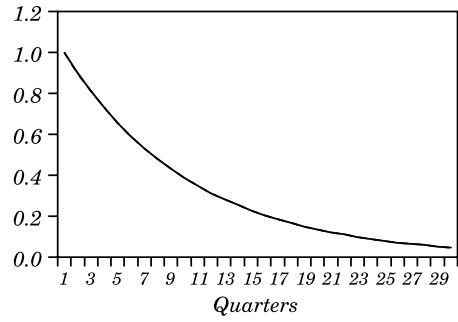

C. Inflation

Percent deviation from steady state

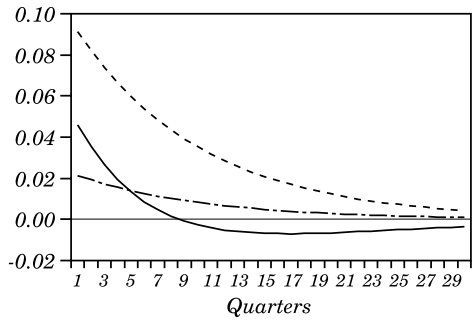

E. Price level

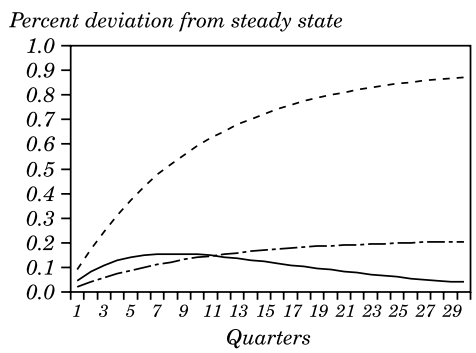

B. Output

Percent of steady-state output

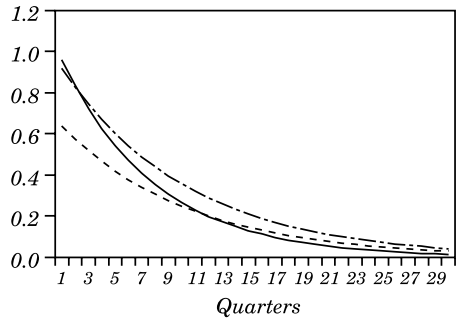

D. Policy rate

Percent deviation from steady state

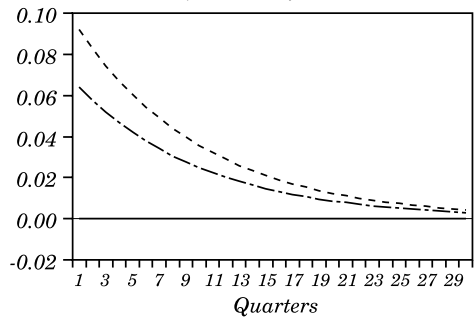

F. Exchange rate

Percent deviation from steady state

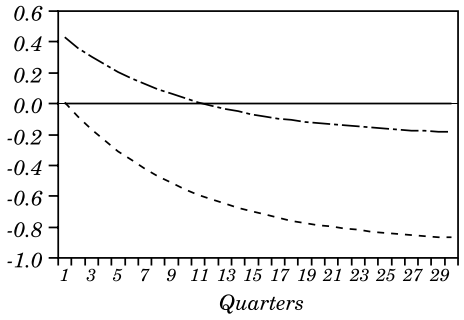

Float $(\phi=1.01)$

Source: Authors' construction. 


\section{Inspecting the Role of Long-Term Real Interest RATES}

To analyze more closely how the transmission of fiscal shocks is bound to depend on the interaction of fiscal and monetary policy over different time horizons, we now turn to a simple analytical characterization of fiscal transmission under a float (cum Taylor rule) and under a peg. The main insight is that fiscal policy cannot be modeled without specifying a medium- and long-term policy framework. Relative to the Mundell-Fleming world, New Keynesian analysis provides a more suitable framework for this purpose, as it assigns a much greater role to optimal intertemporal allocation by households in response to changes in relative prices and, most notably, to the path of real interest rates.

In the baseline New Keynesian model, the optimal path of consumption is characterized by the consumption Euler equation. We use a linearized version of the model (see appendix A) and solve forward, which yields

$$
c_{t}=\frac{1}{\gamma} E_{t} \underbrace{\sum_{s=0}^{\infty}\left(r_{t+s}-\pi_{t+1+s}\right)}_{\equiv \overline{r_{t}}},
$$

where we have used the fact that the economy is stationary and thus always reverts to the steady state (that is, $\lim _{s \rightarrow \infty} C_{t+s}=0$ ). Equation (25) shows that in terms of deviations from the steady state, current consumption is determined by expectations over the entire path of future ex ante real interest rates. Since the expectation hypothesis holds in the model, the latter can be interpreted as a measure of the real return on a bond of infinite duration, that is, as a measure of the long-term real interest rate. ${ }^{11}$

The long-term real rate synthesizes fiscal and monetary interactions across all time horizons, in response to fiscal and other shocks (see Corsetti, Meier, and Müller, 2009). As mentioned, under a float, monetary policy is not constrained by the need to bring the

11. The long-term real interest rate is also tightly linked to the real exchange rate, via risk sharing: $-\gamma c_{t}=q_{t}=\bar{r}_{t}$ (see appendix A). Movements in the long-term interest rate may thus simultaneously rationalize changes in consumption and the real exchange rate. Specifically, Corsetti, Meier, and Müller (2009) discuss how the expected path of future government spending alters the behavior of long-term real interest rates and the short-run adjustment to an exogenous innovation in government spending. 
price level back to its initial steady-state level in the long run. With a Taylor rule in place, the monetary stance in response to a fiscal expansion is contractionary in both the short and long runs, to a degree that depends on the parameterization of coefficient $\phi_{\pi}$. The increase in spending causes inflation to remain persistently positive, so short-term rates are expected to remain above or at their steadystate value over time; this implies a rise in long rates on impact. In appendix $\mathrm{C}$ we show formally that under a float, long-term rates always increase for plausible parameter values, as long as $\psi_{G}=0$.

Consider now the case of a currency peg. As shown in figure 2, monetary policy appears to be more accommodative in the short run under a peg, since in real terms short-term interest rates fall oneto-one with the rise in inflation. Short real rates rise in the medium and long runs, however, when, for an unchanged nominal exchange rate, purchasing power parity drives inflation into negative territory (in deviations from the steady state). Given the dynamics of inflation displayed in figure 2 , for instance, real short-term rates initially fall below steady state, but become positive after about eight quarters.

This observation raises the issue of determining in which direction the long-term rate moves on impact. A simple analytical insight on this question can be derived using our simplifying assumptions (namely, a small open economy and constant foreign variables). Recall that under complete financial markets, the economy is stationary and always reverts to the steady state after a temporary increase in domestic government spending. As PPP holds in the long run, $\lim _{t \rightarrow \infty} P_{t}=P^{*}$ under an exchange rate peg: in the long run, the domestic price level is pinned down by the foreign price level. It follows that

$$
\sum_{t=0}^{\infty} \pi_{t}=0
$$

At the same time, the domestic interest rate is pegged to the foreign rate, the latter being constant by assumption. Therefore,

$$
\bar{r}_{t}=\underbrace{\left(-\sum_{t=0}^{\infty} \pi_{t+1}\right)-\pi_{0}}_{=0}+\pi_{0}=\pi_{0} .
$$

Hence, the response of the real long-term interest rate on impact is equal to the initial, unanticipated change in CPI inflation (and the future evolution of inflation is not relevant). Since the initial effect of 
an increase in government spending on inflation is positive, the longterm rate increases, and consumption cannot but decline. Moreover, a positive differential between domestic and foreign long-term real rates causes the exchange rate to appreciate in real terms.

The above result has a number of implications for the literature on macroeconomic adjustment and stabilization policy under a fixed exchange rate regime. A point in case concerns the so-called Walters critique. This starts from the observation that, holding the nominal interest rate constant, the inflationary effects of a positive demand shock translate into a fall in the short-term real interest rate. The endogenous movement in the real interest rate is expansionary, according to this argument: it boosts demand further, rather than stabilizing it. In its extreme form, the Walters critique states that a small open economy pursuing a currency peg or participating in a currency union becomes unstable, since shocks are amplified by procyclical movements in the monetary stance.

The traditional counterargument points out that with positive domestic inflation, rising prices would eventually crowd out exports, naturally stabilizing demand through the real exchange rate channel. The modern paradigm clarifies a deeper issue. As shown above, under a peg, the long-run real rates, which drive private demand, actually rise one-to-one with the initial bout of inflation. The short-run inflationary consequences of a positive demand shock simultaneously reduce short-term rates in real terms, but these are not directly relevant for private spending decisions.

A reference to the effects of rising prices on competitiveness is still appropriate in the modern framework: competitiveness is the economic force behind PPP. What the New Keynesian model emphasizes is that one cannot contrast the real exchange rate channel and the interest rate channel, treating them as independent of each other. In equilibrium, they both shape the intertemporal price relevant for private consumption and saving decisions.

\section{Overturning the Conventional Wisdom: The Medium-Term Fiscal Framework}

The role of intertemporal prices in the transmission of fiscal policy heightens the importance of broadening the analysis to encompass general specifications of the medium-term frameworkbeyond the case of $\psi_{G}=0$. To explore this new direction of the 
analysis, we draw on Corsetti, Meier, and Müller (2009) and contrast results for $\psi_{G}=0$ and $\psi_{G}=0.02$, while setting $\psi_{T}=0.02$; compare equation (13). With a positive $\psi_{G}$, an expansion of government spending leads to an endogenous adjustment of spending over time. From a quantitative perspective, our assumptions imply that government spending is cut and taxes are increased, by 0.02 basis points for every 1 percent increase in government debt (all measured in units of steady-state output).

For economies with floating exchange rates, the relevance of debt stabilization for the effectiveness of fiscal stimulus cannot be overstated. Corsetti, Meier, and Müller (2009) analyze in detail the implications of endogenous dynamic spending cuts, dubbed spending reversals, and show that the spending multiplier on consumption may be positive on impact: consumption demand is actually crowded in, and the response of output is therefore larger. The transmission mechanism is analogous to the one discussed under the peg in the previous section. Following the same logic as before, we focus on the response of inflation. The inflation rate, which is positive in the short run, turns negative over time (relative to the steady state) in anticipation of spending cuts, and it thus falls even before these cuts are actually implemented. This is because, with sticky prices, forward-looking firms optimally adjust prices downward ahead of the fall in demand. Since lower inflation means lower policy rates relative to the case of $\psi_{G}=0$, a spending expansion in the short run may actually be accompanied by a fall (not a rise) in the long-term interest rate, crowding in private demand and boosting output more than one for one on impact. The exchange rate therefore depreciates, instead of appreciating. This is consistent with a recent body of evidence for economies that have adopted floating exchange rates (see the discussion in Corsetti, Meier, and Müller, 2010).

The Corsetti, Meier, and Müller (2009) case of a spending reversal is especially relevant for present analysis because the consequences for the transmission mechanism differ sharply across exchange rate regimes. figure 4 reports impulse responses for the float and the peg to government spending shocks characterized by reversals (the endogenous behavior of spending over time is shown in panel A). The results contrast sharply with those shown in figure 2, computed in the absence of spending reversals. In particular, the output response, shown in panel $\mathrm{B}$, is apparently at odds with the conventional wisdom: for the first two years, the output response is larger under a float than under a peg. 
Figure 4. Effect of a Government Spending Shock with Spending Reversals: Peg versus Float

\section{A. Goverment spending}

Percent of steady-state output

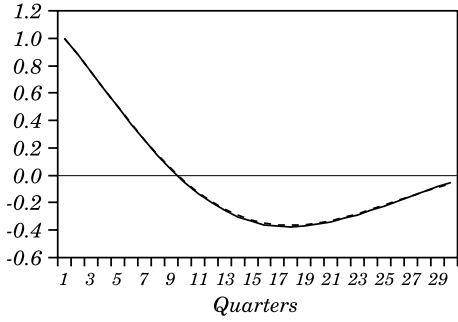

C. Inflation

Percent deviation from steady state

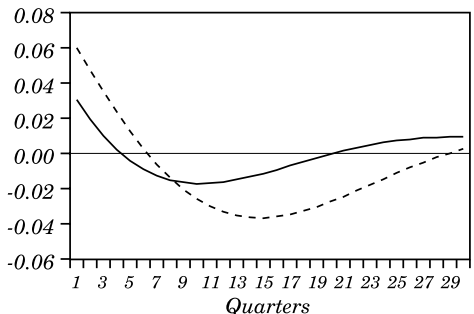

E. Price level

Percent deviation from steady state

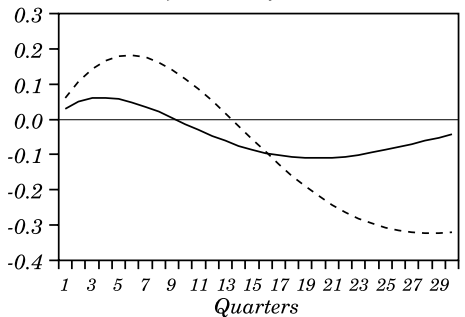

B. Output

Percent of steady-state output

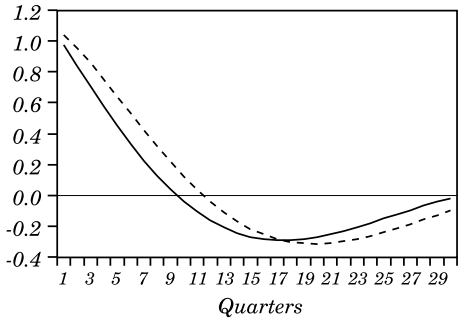

D. Policy rate

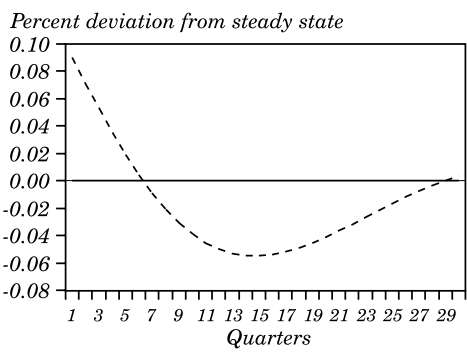

F. Exchange rate

Percent deviation from steady state

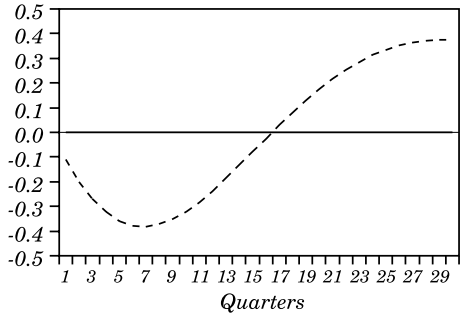

Source: Authors' construction. 
While the regime of debt consolidation (with reversals) is quite consequential for the short-run output effects under a float, it plays no quantitatively important role under a peg. This is consistent with our analytical characterization of the transmission under a peg, according to which the long-term real rate always rises on impact with impact inflation-irrespective of the exact path of future shortterm real rates and thus irrespective of the type and intensity of debt consolidation.

These results add an important dimension to the conventional wisdom on fiscal transmission across exchange rate regimes. Not only does the relative effectiveness of fiscal policy vary with the relative degree of monetary accommodation across regimes, but holding the degree of monetary accommodation constant, the ranking is also sensitive to the specification of the medium-term fiscal outlo

\section{Robustness and Extensions: The Case of Incomplete Financial Markets}

So far, we have developed our analysis under the assumption of complete financial markets. We now explore the extent to which our results are sensitive to financial frictions, using two alternative assumptions regarding the structure of financial markets. First, we relax the assumption that financial markets are complete at the international level and allow for trade in nominally noncontingent bonds only. Second, we assume that in addition, access to domestic financial markets is restricted. Specifically, only a subset of the population has access to asset markets, and households without access consume their disposable income in each period. That setup is similar to the closed-economy variants of Galí, López-Salido, and Vallés (2007) and Bilbiie, Meier, and Müller (2008).

\subsection{Model Setup}

Our model is amended by the assumption that out of a continuum of households in $[0,1]$ residing in our small open economy, a fraction $1-\lambda$ are asset holders, indexed by a subscript $A$. These households own the firms and may trade one-period bonds both domestically and internationally. The remaining households (a fraction, $\lambda$, of the total) do not participate at all in asset markets, that is, they do not hold assets. They are indexed by a subscript $N$. 
A representative asset-holding household chooses consumption, $C_{A, t}$, and supplies labor, $H_{A, t}$, to intermediate-good firms in order to maximize

$$
E_{t} \sum_{k=0}^{\infty} \beta^{k}\left(\frac{C_{A, t+k}^{1-\gamma}}{1-\gamma}-\frac{H_{A, t+k}^{1-\varphi}}{1-\varphi}\right)
$$

subject to the period budget constraint

$$
R_{t}^{-1} A_{t+1}+\frac{R_{F, t}^{-1} B_{t+1}}{\mathrm{NER}_{t}}+P_{t} C_{A, t}=A_{t}+\frac{B_{t}}{\mathrm{NER}_{t}}+W_{t} H_{A, t}-T_{t}+\Upsilon_{t}
$$

where $A_{t}$ and $B_{t}$ are one-period bonds denominated in domestic and foreign currency, respectively. $R_{t}$ and $R_{F, t}$ denote the gross nominal interest rates on both bonds. Ponzi schemes are ruled out by assumption.

We assume that the interest rate paid or earned on foreign bonds by domestic households is determined by the exogenous world interest rate, $R_{t}{ }^{*}$, plus a spread that decreases in the real value of bond holdings scaled by output, that is,

$$
R_{F, t}=R_{t}^{*}-\alpha \frac{B_{t+1}}{\operatorname{NER}_{t} Y_{t} P_{t}}
$$

This assumption ensures the stationarity of bond holdings (even for very small values of $\alpha$ ) and thus allows us to study the behavior of the economy in the neighborhood of a deterministic steady state. ${ }^{12}$

A representative non-asset-holding household chooses consumption, $C_{N, t}$, and supplies labor, $H_{N, t}$, to intermediate-good firms in order to maximize its utility flow on a period-by-period basis. The objective is thus given by

12. Our particular specification draws on Kollman (2002), who studies a model similar to ours. Schmitt-Grohé and Uribe (2003) consider a real model of a small open economy and suggest the above mechanism of a debt-elastic interest rate as one of several ways to close small open economy models (that is, to induce stationarity) with incomplete markets. 
$\max \frac{C_{N, t}^{1-\gamma}}{1-\gamma}-\frac{H_{N, t}^{1+\varphi}}{1+\varphi}$

subject to the constraint that consumption expenditure equals net income:

$$
P_{t} C_{N, t}=W_{t} H_{N, t}-T_{t}
$$

For non-asset-holding households, consumption equals disposable income in each period, and they are thus sometimes also referred to as hand-to-mouth consumers.

Aggregate consumption and labor supply are given by

$\beta \hat{d}_{t+1}^{r}=\hat{d}_{t}^{r}+\chi \omega s_{t}+\hat{g}_{t}-\hat{t}_{t}^{r}$.

and

$H_{t}=\lambda H_{N, t}+(1-\lambda) H_{A, t}$

where $H_{t}=\int_{0}^{1} H_{t}(j) d j$ is aggregate labor employed by domestic intermediate-good firms.

Regarding asset markets, we assume that foreigners do not hold domestic bonds. Market clearing for domestic currency bonds therefore requires

$$
(1-\lambda) A_{t}-D_{t}=0
$$

The market for foreign currency bonds clears by Walras' law.

\subsection{Transmission with Imperfect Risk Sharing}

This section presents model simulations under either incomplete markets or both incomplete markets and limited market participation, as specified above. In appendix A, we provide a detailed list of the equilibrium conditions used in the simulations. We maintain the same parameter values as in section 4 , except for the trade price elasticity $\sigma$. At a value of one for this elasticity 
(assumed above), relative prices move in such a way that they ensure complete risk sharing even under incomplete international asset markets (see Cole and Obstfeld, 1991). Since we are interested in the sensitivity of our results to environments with imperfect risk sharing, we set $\sigma=2 / 3$, a value in the (admittedly wide) range considered in the recent macroeconomics literature. ${ }^{13}$ For the sake of brevity, we focus only on the case of exogenous autoregressive spending shocks with $\psi_{G}=0$ and do not examine the case of spending reversals here.

Figure 5 contrasts the results for the baseline scenario (complete financial markets) with those obtained under the assumption that international financial markets are incomplete. As before, we posit an exogenous increase in government spending by 1 percent of steady-state output (not shown). The response of consumption is somewhat higher with incomplete markets in both exchange rate regimes, corresponding to the different dynamics of long-term real interest rates. From a quantitative perspective, however, differences in the response of consumption and output are modest. ${ }^{14}$

13. See Corsetti, Dedola, and Leduc (2008) for further discussion.

14. This finding is in line with earlier research, which finds that the allocation under incomplete financial markets is quite close to the allocation under complete markets, unless the trade price elasticity is substantially different from one on either side and, for the case of a high elasticity, shocks are persistent or follow a diffusion process (see Corsetti, Dedola, and Leduc, 2008). 
Figure 5. Effect of a Government Spending Shock under Complete and Incomplete International Financial Markets

A. Private Consumption: Float

Percent of steady-state output

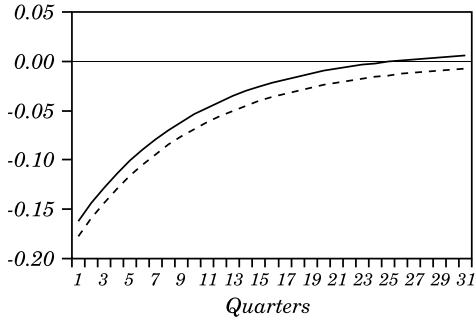

C. Output: Float

Percent of steady-state output

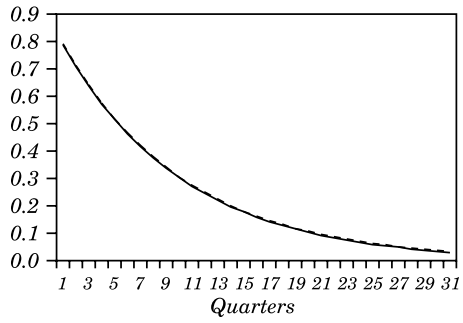

E. Real exchange rate: Float

Percent deviation from steady state

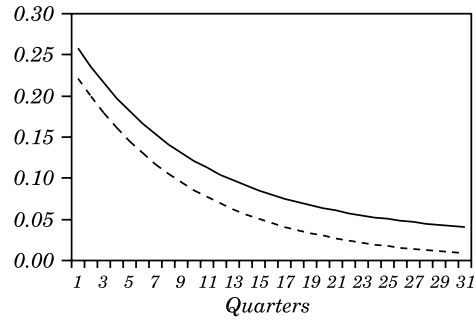

Baseline scenario
B. Private Consumption: Peg

Percent of steady-state output

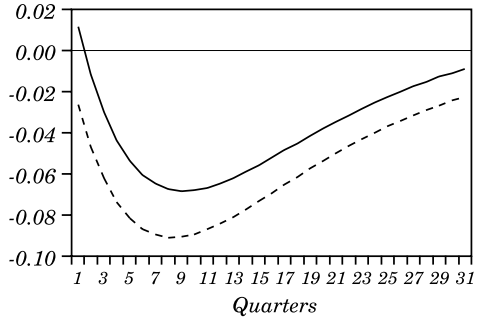

D. Output: Peg

Percent of steady-state output

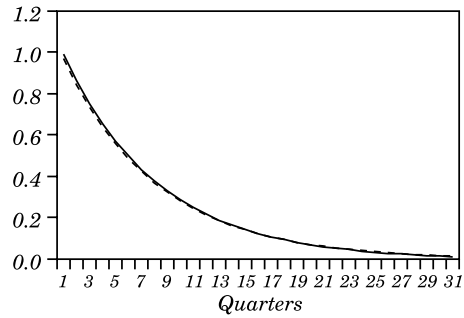

F. Real exchange rate: $P$ eg

Percent deviation from steady state

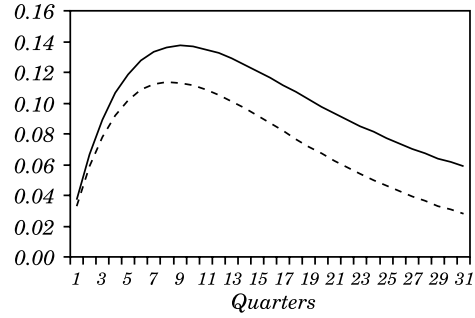

Incomplete markets

Source: Authors' construction. 


\subsection{Limited Asset-Market Participation}

Figure 6 contrasts the results for the baseline scenario (complete financial markets) with the case of limited participation. In this case, we assume both that the set of assets traded across countries is restricted to trade in noncontingent bonds and that access to trade in bonds wthin a country is restricted, so that only a fraction $1-\lambda$ has access. Specifically, we assume that $\lambda=1 / 3$. We report the responses of consumption, long-term real interest rates, and output to an exogenous increase in government spending by 1 percent of GDP.

With limited asset market participation, the dynamic adjustment of consumption is quite different from our results in section 4 . On impact, consumption now increases, both under the float and under the peg. Importantly, this occurs despite the fact that the response of long-term real rates is actually positive throughout. The reason is straightforward: in our specification, a considerable fraction of households do not have access to asset markets. Their consumption is a function of current income and not directly linked to changes in long-term interest rates. Because of the strong consumption response, we also find a considerably stronger effect of government spending on output. This model variant thus lends support to the conventional wisdom: absent a reversal of spending (with $\psi_{G}=0$ ) the macroeconomic transmission of fiscal shocks is somewhat stronger under the peg, with an impact multiplier above one. 


\section{Figure 6. Effect of a Government Spending Shock under Unrestricted and Restricted Financial Markets ${ }^{a}$}

\section{A. Private Consumption: Float}

Percent deviation from steady state

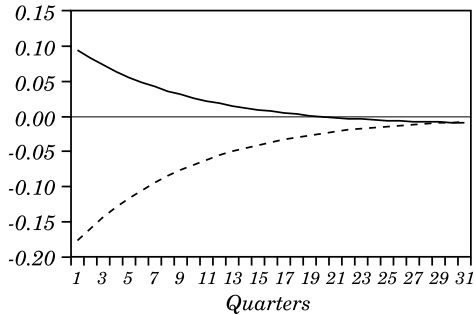

C. Output: Float

Percent deviation from steady state

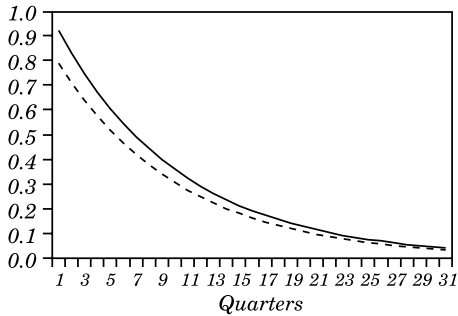

E. Real exchange rate: Float

Percent deviation from steady state

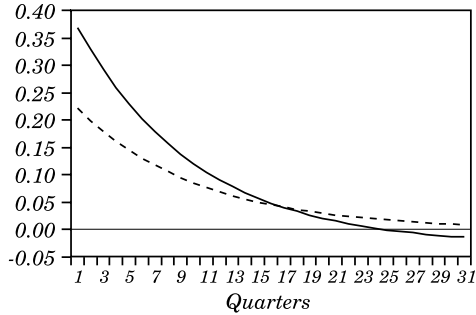

Baseline scenario
B. Private Consumption: Peg

Percent deviation from steady state

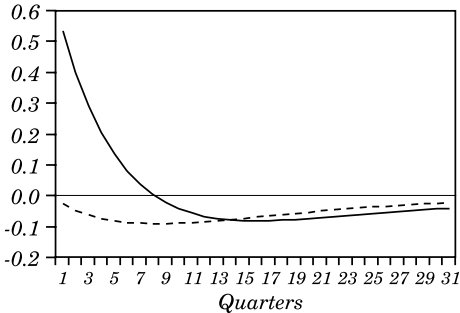

D. Output: Peg

Percent deviation from steady state

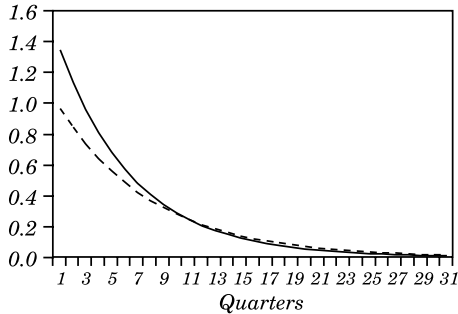

F. Real exchange rate: $P$ eg

Percent deviation from steady state

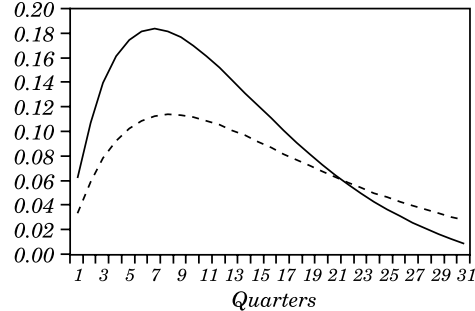

Incomplete markets

Source: Authors' construction.

a. Restricted markets assume that at the international level only bonds are traded and $\lambda=1 / 3$. 


\section{Conclusions}

Does a fixed exchange rate regime enhance the ability of fiscal policies to determine economic activity? Can small countries in the euro area expect more from fiscal stabilization than countries outside the area? Decades of practice in economic policy have already qualified the affirmative answers that textbook treatments of the Mundell-Fleming model provide to these questions. In this paper, we have explored theoretical reasons for reframing the conventional wisdom in a still richer way.

Building on Corsetti, Meier, and Müller (2009), our analysis brings a simple insight to bear on the role of the exchange rate regime for fiscal policy transmission: the effectiveness of fiscal stimulus depends on the medium-term policy framework, that is, on both monetary and fiscal policies over the medium term. In particular, the short-run effect of fiscal measures not only depends on the exchange rate regime and the monetary strategy more generally, but also hinges on the future fiscal mix. The main message of the conventional wisdom was that one cannot assess fiscal stimulus independently of the exchange rate regime. We have shown here that this message needs to be extended to include both the monetary regime and the medium-term fiscal regime.

As a result of fiscal and monetary interactions, the textbook rendition of the conventional wisdom cannot be taken at face value. For example, if budget adjustments are implemented through spending cuts in addition to tax hikes (the empirical relevance of which was highlighted in Corsetti, Meier, and Müller, 2009), the anticipation of a future retrenchment of government spending tends to magnify the output effects of fiscal expansions under flexible exchange rates. Such anticipation has limited or no effects under a peg, however, as we show in the current paper. These results raise a number of analytical, empirical, and policy issues, which, when properly addressed, should help define the preconditions for successful fiscal stabilization.

Our analysis in this paper has abstracted from the possibility that monetary policy is constrained by the zero lower bound on policy rates. Recent research by Christiano, Eichenbaum, and Rebelo (2009) and others within a closed economy context illustrates that government spending can be a much more effective stabilization tool when monetary policy is constrained. In that context, we have shown in related work of ours that spending reversals of the kind 
analyzed in section 6 of this paper are likely to enhance the shortrun effects of fiscal stimulus when the zero lower bound is binding, provided that they are not phased in too early along the recovery path (Corsetti and others 2010). A detailed analysis of the interaction of fiscal and monetary policy in a small open economy that takes the zero lower bound constraint into account is certainly an important direction of research. In light of our earlier work, we conjecture that such an analysis will further strengthen the case for fiscal policy as a stabilization tool, especially under floating exchange rates. 
APPENDix A

\section{Equilibrium Conditions of the Linearized Model}

This appendix outlines the linearization of the model and states the equilibrium conditions used in the simulations. Lowercase letters denote percentage deviations from steady-state values; hats denote deviations from steady-state values scaled by steady-state output. Throughout we assume that variables in the rest of the world are constant. We consider the model that allows for a fraction of households without access to asset markets (see section 7.2), which nests the model with full asset market participation for $\lambda=0$.

\section{A.1 Definitions and derivations}

Price indexes. The law of one price, the terms of trade, the consumption price index, and CPI inflation can be written as

$$
\begin{aligned}
& p_{F, t}=p_{t}^{*}-\mathrm{NER}_{t} s, \\
& s_{t}=p_{H, t}-p_{F, t}, \\
& p_{t}=(1-\omega) p_{H, t}+\omega p_{F, t}=p_{H, t}-\omega s_{t}, \\
& \pi_{t}=\pi_{H, t}-\omega \Delta s_{t},
\end{aligned}
$$

and

$$
q_{t}=(1-\omega) s_{t},
$$

where $q_{t}$ measures the real exchange rate.

Intermediate-good firms. The production function of intermediate goods is given by $Y_{t}(j)=H_{t}(j)$. Using equations (15) in (14) gives the demand function for a generic good $j$,

$$
Y_{t}(j)=\left[\frac{P_{H, t}(j)}{P_{H, t}}\right]^{-\varepsilon} Y_{t},
$$


so that

$$
\int_{0}^{1} Y_{t}(j) d j=\zeta_{t} Y_{t}
$$

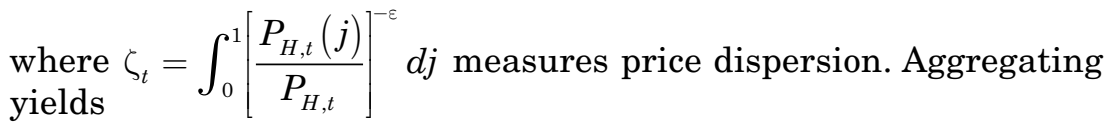

$$
\zeta_{t} Y_{t}=\int_{0}^{1} H(j)_{t} d j=H_{t}
$$

A first-order approximation is given by $y_{t}=h_{t}$.

The first-order condition to the price-setting problem is given by

$$
E_{t} \sum_{k=0}^{\infty} \xi^{k} \rho_{t, t+k}\left[Y_{t, t+k}(j) P_{H, t}(j)-\frac{\varepsilon}{\varepsilon-1} W_{t+k} H_{t+k}\right]=0 .
$$

In the steady state, we have a symmetric equilibrium:

$$
P_{H}=\frac{\varepsilon}{\varepsilon-1} \frac{W H}{Y}=\frac{\varepsilon}{\varepsilon-1} M C^{n},
$$

where the second equation defines nominal marginal costs.

Linearizing equation (A.9) and using the definition of price indexes, one obtains a variant of the New Keynesian Phillips curve (see, for example, Galí and Monacelli, 2005):

$$
\pi_{H, t}=\beta E_{t} \pi_{H, t+1}+\kappa m c_{t}^{r},
$$

where $\kappa=(1-\xi)(1-\beta \xi) / \xi$ and marginal costs are defined in real terms, deflated with the domestic price index,

$$
m c_{t}^{r}=w_{t}-p_{H, t}=w_{t}^{r}-\omega s_{t} .
$$

Here $w_{t}^{r}=w_{t}-p_{t}$ is the real wage (deflated with the CPI).

Profits per capita are defined as follows

$$
\Upsilon_{t}^{p c}=P_{H, t} Y_{t}-W_{t} H_{t}
$$


Linearized we have (deflated with the CPI)

$$
\hat{\Upsilon}_{t}^{r, p c}=\omega s_{t}+y_{t}-\frac{\varepsilon-1}{\varepsilon}\left(w_{t}^{r}+h_{t}\right) .
$$

Households. The first-order conditions in deviations from the steady state are familiar:

$$
\begin{aligned}
& w_{t}-p_{t}=\gamma c_{A, t}+\varphi h_{A, t} ; \\
& c_{A, t}=E_{t} c_{A, t+1}-\frac{1}{\gamma}\left(r_{t}-E_{t} \pi_{t+1}\right) .
\end{aligned}
$$

In terms of output units (defining $\chi \equiv G / Y$ ), this becomes

$$
\begin{aligned}
& (1-\chi) w_{t}^{r}=\gamma \hat{c}_{A, t}+(1-\chi) \varphi h_{A, t} ; \\
& \hat{c}_{A, t}=E_{t} \hat{c}_{A, t+1}-\frac{(1-\chi)}{\gamma}\left(r_{t}-E_{t} \pi_{t+1}\right) .
\end{aligned}
$$

The first-order conditions for non-asset-holding households are

$$
\begin{aligned}
& P_{t} C_{N, t}=W_{t} H_{N, t}-T_{t} ; \\
& C_{N, t}=\frac{W_{t}}{P_{t}} H_{N, t}-T_{t}^{R} .
\end{aligned}
$$

The first-order approximation is

$$
Y \hat{c}_{N, t}=\frac{W H}{P}\left(w_{t}^{r}+h_{N, t}\right)-Y \hat{t}_{t}^{r},
$$

or after rearranging

$$
\hat{c}_{N, t}=\frac{\varepsilon-1}{\varepsilon}\left(w_{t}^{r}+h_{N, t}\right)-\hat{t}_{t}^{r} .
$$

The first-order condition for labor supply is given by

$$
(1-\chi) w_{t}^{r}=\gamma \hat{c}_{N, t}+(1-\chi) \varphi h_{N, t}
$$


Regarding international financial markets, we consider as the baseline scenario a complete set of assets. In this case, consumption is tightly linked to the real exchange rate (see, for example, Galí and Monacelli, 2005):

$$
\gamma c_{A, t}=-q_{t}
$$

Alternatively, we assume that there is trade in nominally riskless bonds only. In this case, we have to keep track of the net foreign asset position, using the flow budget constraint of asset holders:

$$
R_{t}^{-1} A_{t+1}+\frac{R_{F, t}^{-1} B_{t+1}^{*}}{\mathrm{NER}_{t}}+P_{t} C_{A, t}=A_{t}+\frac{B_{t}^{*}}{\mathrm{NER}_{t}}+W_{t} H_{A, t}-T_{t}+\psi_{t} .
$$

Recall that $D_{t}=(1-\lambda) A_{t} \theta$, that is, government debt is held by domestic asset holders, and that profits go to asset holders only: $(1-\lambda) \psi_{t}=\psi_{t}^{p c}$. Linearization around the zero debt steady state gives

$$
\frac{\beta \hat{d}_{t+1}^{r}}{(1-\lambda)}+\beta \hat{b}_{t+1}^{r}+\hat{c}_{A, t}=\frac{\hat{d}_{t}^{r}}{(1-\lambda)}+\hat{b}_{t}^{r}+\frac{\varepsilon-1}{\varepsilon}\left(w_{t}+h_{A, t}\right)-\hat{t}_{t}^{r}+\frac{\hat{\Upsilon}_{t}^{r, p c}}{(1-\lambda)}
$$

Uncovered interest rate parity would imply: $r_{t}-r_{F, t}=-\Delta E_{t}$ ner $_{t+1}$, but interest rates on foreign currency bonds (assuming constant world interest rates) are given by

$$
r_{F, t}=-\alpha \frac{B_{t+1}}{\beta Y \mathrm{NER}_{t} P_{t}},
$$

such that

$$
r_{t}+\alpha \beta \hat{b}_{t+1}^{r}=-\Delta E_{t} \mathrm{NER}_{t+1} .
$$

Government. Rewriting the interest rate feedback rule in terms of deviations from the steady state (with zero inflation), we have under a float

$$
r_{t}=\phi \pi_{H, t}
$$


Recall that $r_{t}=\left(R_{t}-R\right) / R$. Rewriting the fiscal rules gives

$$
\frac{G_{t}-G}{Y}=\rho \frac{G_{t-1}-G}{Y}-\psi_{G} \frac{D}{Y P_{t-1}}+\varepsilon_{g, t}
$$

and

$$
T_{r, t}=\phi_{T} \frac{D_{t}}{P_{t-1}}
$$

or

$$
\hat{g}_{t}=\rho \hat{g}_{t-1}-\psi_{G} \hat{d}_{t}^{r}+\varepsilon_{t}
$$

and

$\hat{t}_{t}^{r}=\psi_{T} \hat{d}_{t}^{r}$

Finally, the government budget constraint is given by

$$
\beta \hat{d}_{t+1}^{r}=\hat{d}_{t}^{r}+\chi \omega s_{t}+\hat{g}_{t}-\hat{t}_{t}^{r} .
$$

Equilibrium and additional definitions. Good-market clearing (equation 15) in terms of deviations from steady state is given by

$$
y_{t}=-\sigma(1-\omega) \omega(1-\chi) s_{t}+(1-\omega) \hat{c}_{t}-\omega \sigma(1-\chi) s_{t}+\omega \hat{c}_{t}^{*}+\hat{g}_{t} .
$$

Rearranging under the assumption that rest of the world variables are constant, we have

$$
y_{t}=-(2-\omega) \sigma \omega(1-\chi) s_{t}+(1-\omega) \hat{c}_{t}+\hat{g}_{t} .
$$

We define trade balance in percent of steady state output:

$$
T B_{t}=\frac{P_{H, t} Y_{t}-P_{t} C_{t}-P_{H, t} G_{t}}{P_{H, t} Y}=\frac{Y_{t}-C_{t}\left(P_{t} / P_{H, t}\right)-G_{t}}{Y} .
$$


Approximatively, around the steady state we have

$$
\widehat{t b}_{t}=y_{t}-\hat{c}_{t}+(1-\chi) \omega s_{t}-\hat{g}_{t} .
$$

\section{A.2 Equilibrium conditions used in model simulation}

Optimality of household behavior implies

$$
\begin{aligned}
& \gamma \hat{c}_{A, t}=\gamma E_{t} \hat{c}_{A, t+1}-(1-\chi)\left(r_{t}-E_{t} \pi_{t+1}\right) ; \\
& \hat{c}_{N, t}=\frac{(\varepsilon-1)}{\varepsilon}\left(w_{t}^{r}+h_{N, t}\right)-\hat{t}_{t}^{r} ; \\
& \hat{c}_{t}=\lambda \hat{c}_{N, t}+(1-\lambda) \hat{c}_{A, t} ; \\
& \left(1-g_{t}\right) w_{t}^{r}=\gamma \hat{c}_{A, t}+(1-\chi) \varphi h_{A, t} ; \\
& \left(1-g_{t}\right) w_{t}^{r}=\gamma \hat{c}_{N, t}+(1-\chi) \varphi h_{N, t} ; \\
& h_{t}=\lambda h_{N, t}+(1-\lambda) h_{A, t} .
\end{aligned}
$$

Asset market structures differ across simulations. For incomplete financial markets, we need the budget constraint of asset holders (equation A.26) and the uncovered interest rate parity condition (equation A.27)

$$
\begin{aligned}
& \frac{\beta \hat{d}_{t+1}^{r}}{(1-\lambda)}+\beta \hat{b}_{t+1}^{r}+\hat{c}_{A, t}=\frac{\hat{d}_{t}^{r}}{(1-\lambda)}+\hat{b}_{t}^{r}+\frac{\varepsilon-1}{\varepsilon}\left(w_{t}^{r}+h_{A, t}\right)-\hat{t}_{t}^{r}+\frac{\hat{\Psi}_{t}^{r, p c}}{1-\lambda} \\
& r_{t}+\alpha \beta \hat{b}_{t+1}^{r}=-\Delta E_{t} \mathrm{NER}_{t+1} .
\end{aligned}
$$

Under complete markets, we use the risk-sharing condition (A.24) and zero foreign bond holdings:

$$
\gamma \hat{c}_{A, t}=-(1-\chi) q_{t}
$$


$\hat{b}_{t+1}=0$.

Intermediate-good firms' behavior is governed by marginal costs (equation A.12), the Philips curve (equation A.11), and the production function:

$m c_{t}^{r}=w_{t}^{r}-\omega s_{t} ;$

$\pi_{H, t}=\beta E_{t} \pi_{H, t+1}+\kappa m c_{t}^{r} ;$

$y_{t}=h_{t}$.

Government policies (equations A.28, A.29, and A.30), the government budget constraint (equation A.31), and market clearing (equation A.33) are given by

$r_{t}=\phi \pi_{H, t} \quad$ or $\quad \mathrm{NER}_{t}=0$

$\hat{t}_{t}^{r}=\psi_{t} \hat{d}_{t}^{r}$

$\hat{g}_{t}=\rho \hat{g}_{t-1}-\psi_{G} \hat{d}_{t}^{r}+\varepsilon_{t} ;$

$\beta \hat{d}_{t+1}^{r}=\hat{d}_{t}^{r}+\chi \omega s_{t}+\hat{g}_{t}-\hat{t}_{t}^{r} ;$

$y_{t}=-(1-\chi)(2-\omega) \sigma \omega s_{t}+(1-\omega) \hat{c}_{t}+\hat{g}_{t}$.

Definitions for the trade balance, relative prices, inflation, and profits are given by

$$
\begin{aligned}
& t b_{t}=y_{t}-\hat{c}_{t}+(1-\chi) \omega s_{t}-\hat{g}_{t} ; \\
& \pi_{t}=\pi_{H, t}-\omega \Delta s_{t} ; \\
& \Delta \mathrm{NER}_{t}=(1-\omega) \Delta s_{t}-\pi_{t} ;
\end{aligned}
$$




$$
q_{t}=(1-\omega) s_{t}
$$

$$
\hat{\Psi}_{t}^{p c, r}=\omega s_{t}+y_{t}-\frac{\varepsilon-1}{\varepsilon}\left(w_{t}^{r}+h_{t}\right) .
$$


APPENDIX B

\section{Key Equations of the Simple Model}

In this appendix, we reduce the number of equations that characterize the equilibrium in order to obtain the canonical representation used in section 2 . We only consider the case $\lambda=0$.

\section{B.1 Dynamic IS}

Combining good-market clearing and the risk-sharing condition, $\gamma c_{t}=-(1-\omega) s_{t}$, gives

$$
y_{t}=-\frac{1-\chi}{\gamma} \underbrace{[1+\omega(2-\omega)(\sigma \gamma-1)}_{\equiv \omega}] s_{t}+\hat{g}_{t} .
$$

Hence, we have

$$
s_{t}=-\frac{\gamma}{(1-\chi) \varpi}\left(y_{t}-\hat{g}_{t}\right),
$$

which is equation (24) in the main text

Alternatively, we substitute for the terms of trade to obtain

$$
c_{t}=\frac{1-\omega}{\varpi(1-\chi)}\left(y_{t}-\hat{g}_{t}\right) .
$$

This is helpful in rewriting the Euler equation:

$$
\begin{aligned}
c_{t} & =E_{t} c_{t+1}-\frac{1}{\gamma}\left[r_{t}-E_{t}\left(\pi_{H, t+1}-\omega \Delta s_{t+1}\right)\right] \\
& =E_{t} c_{t+1}-\frac{1}{\gamma}\left[r_{t}-E_{t} \pi_{H, t+1}-\frac{\omega \gamma}{(1-\chi) \varpi} E_{t}\left(\Delta y_{t+1}-\Delta \hat{g}_{t+1}\right)\right],
\end{aligned}
$$

where we use $\pi_{t}=\pi_{H, t}-\omega \Delta s_{t}$ in the first equation.

Substituting for consumption gives

$$
y_{t}=E_{t} y_{t+1}-E_{t} \Delta \hat{g}_{t+1}-\frac{(1-\chi) \varpi}{\gamma}\left(r_{t}-E_{t} \pi_{H, t+1}\right),
$$

which is equation (17) in the main text. 
Floats, Pegs, and the Transmission of Fiscal Policy

\section{B.2 Phillips curve}

Consider once more marginal costs:

$$
\begin{aligned}
m c_{t}^{r} & =w_{t}^{r}-\omega s_{t}=-s_{t}+\varphi y_{t} \\
& =\frac{\gamma}{(1-\chi) \varpi}\left(y_{t}-\hat{g}_{t}\right)+\varphi y_{t} .
\end{aligned}
$$

Substituting in equation (A.11) gives equation (18) in the main text. 


\section{APPENDIX C}

\section{Long-Term Interest Rates under Floating Exchange Rates}

This appendix focuses on the response of long-term real interest rates in the case of exogenous government spending. Under a float, the allocation is characterized by equations (17), (18), and the Taylor rule (equation 19). Assuming $\psi_{G}=0$, we solve the model using the method of undetermined coefficients. Assuming that $y_{t}=\phi_{y g} \hat{g}_{t}$ and $\pi_{H, t}=\phi_{\pi g} \hat{g}_{t}$ and substituting in (17) yields

$$
\hat{\sigma}(1-\rho) \phi_{y g}=-\left(\phi_{\pi}-\rho\right) \phi_{\pi g}+\hat{\sigma}(1-\rho),
$$

where $\hat{\sigma} \equiv \gamma /((1-\chi) \varpi)$. This will be positive if $\varpi>0$, which in turn requires $1>\varpi(2-\omega)(1-\sigma \gamma)$ (which we assume to be satisfied).

Substituting in equation (18) gives

$$
\phi_{y g}=\frac{(1-\beta \rho) \phi_{\pi g}+\kappa \hat{\sigma}}{\kappa(\hat{\sigma}+\varphi)} .
$$

Combining the two expressions yields the result

$$
\phi_{\pi g}=\frac{\hat{\sigma}(1-\rho) \varphi \kappa}{\hat{\sigma}(1-\rho)(1-\beta \rho)+\kappa(\varphi+\hat{\sigma})\left(\phi_{\pi}-\rho\right)}>0
$$

as long as $\rho<1$ and $\phi_{\pi}>0$ (which we assume throughout).

As shown in the main text (see equation 25), an expression of long-term real interest rates is given by

$$
\bar{r}_{t}=E_{t} \sum_{s=0}^{\infty}\left(r_{t+s}-\pi_{t+1+s}\right)=E_{t} \sum_{s=0}^{\infty}\left[r_{t+s}-\left(\pi_{H, t+s+1}-\omega \Delta s_{t+s+1}\right)\right]
$$

where the second equality follows from equation (B.2).

Given the solution of the model, we have

$$
E_{t} r_{t+s}=\phi_{\pi} \phi_{\pi g} \rho^{s} \hat{g}_{t}
$$


$E_{t} \pi_{H, t+s+1}=\phi_{\pi g} \rho^{s+1} \hat{g}_{t}$,

and

$E_{t} \Delta s_{t+s+1}=\hat{\sigma}\left(1-\phi_{y g}\right)(\rho-1) \rho^{s} \hat{g}_{t}$,

where the last relationship follows from equation (B.1). Substituting in equation (C.1) gives (after some algebra)

$$
\bar{r}_{t}=\underbrace{\frac{(1-\omega)\left(\phi_{\pi}-\rho\right) \phi_{\pi g}}{1-\rho}}_{>0} \hat{g}_{t}
$$

That is, long-term rates always increase in response to government spending innovations under a float (as long as $\psi_{\mathrm{G}}=0$ ). 


\section{REFERENCES}

Benigno, G., P. Benigno, and F. Ghironi. 2007. "Interest Rate Rules for Fixed Exchange Rate Regimes." Journal of Economic Dynamics and Control 31(7): 2196-211.

Bilbiie, F.O., A. Meier, and G.J. Müller. 2008. "What Accounts for the Changes in U.S. Fiscal Policy Transmission?" Journal of Money, Credit, and Banking 40(7): 1439-69.

Buiter, W., G. Corsetti, and P. Pesenti. 1998. Interpreting the ERM Crisis: Country-Specific and Systemic Issues. Princeton University. Calvo, G.A. 1983. "Staggered Prices in a Utility Maximizing Framework." Journal of Monetary Economics 12(3): 383-98.

Christiano, L., M. Eichenbaum, and S. Rebelo. 2009. "When Is the Government Spending Multiplier Large?” Working Paper 15394. Cambridge, Mass.: National Bureau of Economic Research.

Cole, H. and M. Obstfeld. 1991. "Commodity Trade and International Risk Sharing: How Much Do Financial Markets Matter?” Journal of Monetary Economics 28(1): 3-24.

Corsetti, G., L. Dedola, and S. Leduc. 2008. "International Risk-Sharing and the Transmission of Productivity Shocks." Review of Economic Studies 75(2): 443-73.

Corsetti, G., K. Kuester, A. Meier, and G.J. Müller. 2010. "Debt Consolidation and Fiscal Stabilization of Deep Recessions." American Economic Review 100(2): 41-45.

Corsetti, G., A. Meier, and G.J. Müller. 2009. "Fiscal Stimulus with Spending Reversals.” Working Paper 09/106. Washington: International Monetary Fund.

.2010. "What Determines Government Spending Multipliers?" Cambridge University.

De Paoli, B. 2009. "Monetary Policy and Welfare in a Small Open Economy." Journal of International Economics 77(1): 11-22.

Dornbusch, R. 1980. "Exchange Rate Economics: Where Do We Stand?" Brookings Papers on Economic Activity 1: 143-85.

Eichenbaum, M. and J.D.M. Fisher. 2007. "Estimating the Frequency of Price Re-optimization in Calvo-Style Models." Journal of Monetary Economics 54(7): 2032-47.

Galí, J., M. Gertler, and J.D. López-Salido. 2001. "European Inflation Dynamics." European Economic Review 45(7): 1237-70.

Galí, J., J.D. López-Salido, and J. Vallés. 2007. "Understanding the Effects of Government Spending on Consumption." Journal of the European Economic Association 5(1): 227-270. 
Galí, J. and T. Monacelli. 2005. "Monetary Policy and Exchange Rate Volatility in a Small Open Economy." Review of Economic Studies 72(3): 707-34.

- 2008. "Optimal Monetary and Fiscal Policy in a Currency Union." Journal of International Economics 76(1): 116-32.

Ghironi, F. 2000. "Alternative Monetary Rules for a Small Open Economy: The Case of Canada." Working Paper 466. Boston College.

Kollmann, R. 2002. "Monetary Policy Rules in the Open Economy: Effects on Welfare and Business Cycles." Journal of Monetary Economics, 49(5): 989-1015.

Nakamura, E. and J. Steinsson. 2008. "Five Facts about Prices: A Reevaluation of Menu Cost Models." Quarterly Journal of Economics 123(4): 1415-64.

Newman, P., M. Milgate, and J. Eatwell, eds. 1992. The New Palgrave Dictionary of Money and Finance, Basingstoke: Palgrave Macmillan.

Schmitt-Grohé, S. and M. Uribe. 2003. "Closing Small Open Economy Models.” Journal of International Economics 61(1): 163-85.

Woodford, M. 2003. Interest and Prices. Princeton University Press. 